\title{
Multiple-group membership: warmth and competence perceptions in the workplace
}

\author{
Andrea Strinić $^{1} \cdot$ Magnus Carlsson $^{2}$ • Jens Agerström ${ }^{3}$
}

Published online: 15 August 2020

(C) The Author(s) 2020

\begin{abstract}
What kinds of stereotypes are evoked when employers review a job application from a 55-year-old Arab woman? Most previous research on stereotypes has focused on single demographic group categories (e.g., race or gender) rather than on their combinations, even though people inevitably belong to multiple group categories simultaneously. The current study examines how different combinations of demographic group categories (ethnicity, gender, sexual orientation, and age) are perceived in the context of the workplace, with a focus on two fundamental dimensions of social perception: warmth and competence. The results reveal interesting interactions among the studied demographic group categories such that when stigmatized group categories are added to one another, it does not necessarily produce additive negative effects on warmth and competence perceptions. Rather, one category that is perceived negatively in isolation (e.g., homosexuality) can offset the negative impact of another stigmatized category (e.g., Arab ethnicity). Practical implications for stereotyping and discrimination in the workplace are discussed.
\end{abstract}

Keywords Warmth $\cdot$ Competence $\cdot$ Stereotype content model $\cdot$ Multiple-group membership $\cdot$ Hiring $\cdot$ Stereotypes

Prolific research on the stereotype content model (SCM) shows that people perceive social groups and individuals in terms of how warm (e.g., friendly, trustworthy, and kind) and competent (e.g., intelligent, skillful, and efficient) they are (Cuddy, Glick, \& Beninger, 2011; Fiske, Cuddy, Glick, \& $\mathrm{Xu}, 2002$; Fiske, Xu, Cuddy, \& Glick, 1999). The SCM claims that warmth and competence ${ }^{1}$ are two dimensions that

\footnotetext{
${ }^{1}$ Dimensions of warmth and competence draw their roots from social perception research and have, together with many other concepts, been recognized as similar and indicative of the Big Two dimensions of agency and communion as an overarching framework of social perception in psychology (Abele \& Wojciszke, 2018). We recognize that warmth and competence have been marked as facets of agency and communion in some lines of research (Abele et al., 2016). In the current study, we use the SCM terminology, as it seems to have been most frequently adopted by previous research on the stereotype content of social groups.
}

Andrea Strinić

andrea.strinic@lnu.se

1 Department of Psychology, Faculty of Health and Life Sciences, Linnaeus University, 35195 Växjö, Sweden

2 Department of Economics and Statistics, School of Business and Economics, Linnaeus University, Kalmar, Sweden

3 Department of Psychology, Faculty of Health and Life Sciences, Linnaeus University, Kalmar, Sweden systematically reflect the content of stereotypes associated with diverse social groups. Evidence supporting the model has been obtained using explicit and implicit measures (Carlsson \& Björklund, 2010), in different cultures (Bye, Herrebrøden, Hjetland, Røyset, \& Westby, 2014; Cuddy et al., 2009), with a nationally representative U.S. sample (Cuddy, Fiske, \& Glick, 2007), and from a number of diverse convenience samples (Fiske et al., 2002). The model has received ample support and addresses several complexities associated with perceptions of different groups and individuals in society. It accounts for positive, negative, and mixed (ambivalent) stereotypes and, together with its BIAS map extension, makes predictions about potential emotions, prejudices, and behaviors directed at perceived groups (Cuddy et al., 2007; Fiske, Cuddy, \& Glick, 2007).

Thus far, SCM research has mostly examined how people perceive single demographic group categories (e.g., elderly, the disabled, and gay people) in terms of warmth and competence (for a more recent review, see Fiske, 2018). Perceptions of groups that consist of multiple categories, such as gay men and disadvantaged Black people, have also been studied to some extent, though less systematically than single categories. That is, relatively few studies have examined how the successive addition of categories influences people's warmth and competence perceptions. For example, what happens to 
people's perceptions of Arabs when homosexuality (versus heterosexuality) is also signaled? Furthermore, are these perceptions affected by the gender of the social target? These are arguably important research questions because the targets of our social perception inevitably belong to multiple groups simultaneously.

Another complexity yet to be addressed concerns how the dimensions of warmth and competence interact when an individual is a member of multiple social groups with conflicting stereotype content. Fiske et al. (2002) show that businesswomen are seen as more competent than warm, although the generic category women are perceived as less competent than that of men. If another category is added, will such perceptions be complicated further? For example, what happens if we add Arab ethnicity, which typically ends up in the middle of the warmth/competence space? How will an older Arab businesswoman be perceived in terms of warmth and competence given that older workers as a single category have been found to be perceived as warmer but less competent than younger workers (Krings, Sczesny, \& Kluge, 2011)?

Cuddy et al. (2011) propose that warmth/competence perceptions of groups may be of relevance for various organizational outcomes such as personnel selection and for both role and task assignment. They propose that decisions may be influenced by matching the stereotype content of a demographic group to the particular job/task at hand. As an illustration, Cuddy et al. (2011) note that women, who are regarded as stereotypically warmer than competent, might be hired more often for jobs in which social skills are essential (e.g., cashiers). They also propose that warmth and competence stereotypes may bias evaluations and assessments of employees and affect team functioning, particularly in terms of diversity. Although many propositions have been made, further research is needed to investigate various potential applications in organizational settings. Some initial research has used warmth and competence in an attempt to explain differences in salary recommendations with respect to the ethnicity and sexual orientation of the applicant (Pedulla, 2014). García-Ael, Cuadrado, and Molero (2018) illustrate how the male stereotype (higher competence than warmth) is more congruent with the stereotypes people have of individuals in leadership positions than the female stereotype (more warmth). Krings et al. (2011) shed some light on the role of warmth and competence stereotypes in age discrimination in hiring. They find that younger job candidates are perceived to be both more competent and warmer than older candidates and that this seems to explain why their participants (business students and HR experts) reported a greater willingness to hire younger candidates. Agerström, Björklund, Carlsson, and Rooth (2012) show that compared to Swedish men, Arab men benefit more from explicitly signaling both warmth and competence in their job applications, as doing so raises the probability of their being invited to a job interview. This finding suggests that Swedish hiring managers assume that male Arab applicants lack both warmth and competence until proven otherwise (e.g., by the signaling of these characteristics in a personal letter).

In sum, investigations of warmth/competence perceptions in the workplace have been sporadic and usually directed at the specific goal of comparing one or two demographic groups on a particular outcome (e.g., hiring preferences). An important next step in this line of research is to learn how demographic groups are perceived in the context of work and to investigate how their combinations, i.e., multiplegroup memberships, affect warmth/competence perceptions. The current study explores how professional employees and hiring decision-makers perceive various demographic categories and their intersections in terms of warmth and competence.

\section{Multiple-group membership in the workplace-why employ the SCM?}

Warmth and competence are borne out of the evolutionary need to recognize the intent of others and their capabilities to act on that intent (Fiske et al., 2007). Warmth captures our perceptions of others' intent, or more specifically, how friendly, helpful, trustworthy, sincere, and moral they are (Fiske et al., 2007). Competence captures our perceptions of others' capabilities to act on their intent or, more specifically, how intelligent, skilled, and efficient they are (Fiske et al., 2007). The two dimensions apply to perceptions of both single individuals (person perception) and social groups (stereotypes). The SCM model makes explicit predictions about both emotions and behavioral tendencies directed at groups subject to a particular type of stereotype, and these predictions encompass a large number of diverse demographic groups (Cuddy, Fiske, \& Glick, 2008; Fiske et al., 2002). The model has also been extended to perceptions of various subgroups of immigrants (Lee \& Fiske, 2006), females and males (Eckes, 2002), the elderly (Cuddy, Norton, \& Fiske, 2005), and lesbian and gay groups (Brambilla, Carnaghi, \& Ravenna, 2011; Clausell \& Fiske, 2005; Vaughn, Teeters, Sadler, \& Cronan, 2017). The research on subgroups suggests that even if a generic group is perceived as neutral on both dimensions, ratings of its subgroups can show a more nuanced picture. This indicates that the stereotype content of demographic groups can interact in complex ways. The SCM research per se shows how specifying an additional demographic group can provide important information for the perceiver and change the stereotype content associated with a given category, though few systematic investigations of how multiple-group memberships combine and influence warmth and competence perceptions exist.

Various models/hypotheses of multiple social categorization have been proposed though without incorporating the 
warmth and competence dimensions. Below we provide an overview of models that explicitly incorporate categories of particular relevance to the current research (e.g., gender and ethnicity). The double or multiple jeopardy hypothesis (Beale, 1970; Nelson \& Probst, 2004) predicts that simultaneously belonging to multiple outgroups will increase the chances and severity of discrimination, or more specifically, that belonging to multiple minority groups should have additive effects. Nelson and Probst (2004) suggest that because belonging to minority groups is associated with adverse psychological, physical, and job-related outcomes, the likelihood of experiencing these adverse outcomes increases among individuals with multiple minority status.

Other models suggest that one category becomes dominant and leads perception. The subordinate-male hypothesis predicts that males of subordinate groups will face the most discrimination (Sidanius \& Pratto, 1999). Due to conflict, aggression, and resource competition being more associated with men, Sidanius and Pratto (1999) posit that minority men will experience more discrimination than other groups. They do not aim to trivialize discrimination experienced by minority women but claim that majority men's aggression will be increasingly directed towards minority men.

The ethnic-prominence hypothesis predicts that discrimination will be driven more by race than by gender (Levin, Sinclair, Veniegas, \& Taylor, 2002). This is the case because this category is more salient and more strongly associated with conflict and threat than gender.

Research testing these models shows mixed results and has primarily been developed to propose possible behaviors towards minority groups with a focus on ethnicity and gender rather than explicitly testing how different possible group combinations produce stereotypical perceptions in terms of warmth and competence (e.g., see Derous, Ryan, \& Nguyen, 2012; Derous, Ryan, \& Serlie, 2015). As it stands, the aforementioned multiple categorization models have yet to be integrated with the SCM. Because SCM research shows that the majority of groups have ambivalent (mixed) stereotype content, this implies that multiple categorization models would need to be translated into predictions for both warmth and competence perceptions. Such predictions would seem premature at this point considering the relative lack of research on this topic. Exploratory research on warmth and competence perceptions in relation to multiple groups should, however, provide an additional basis for the future development of predictions that incorporate both dimensions.

\section{Studied groups and research question}

The following group categories are examined in the current study: gender (male/female), ethnicity (Arab/Swedish), sexual orientation (homosexual/orientation not mentioned), age (30- year-old/55-year-old), and their intersections. These categories are widespread in society and commonly studied in research. Furthermore, field experiments in which fictitious job applications are sent to real job openings to investigate discrimination highlight the importance of understanding perceptions of these categories in hiring contexts (Bertrand \& Duflo, 2017), as they demonstrate that recruiters often act on age, ethnicity, gender, and sexual orientation. Hence, these categories were considered relevant for further investigation into how their combinations are perceived.

Perceptions of women are quite diverse according to SCM research. Fiske et al. (2002) show that "traditional" women are targets of paternalistic stereotypes (higher warmth than competence), while businesswomen and feminists are targets of envious stereotypes (higher competence than warmth). The general women category is perceived as higher in warmth than in competence but occupies the in-group quadrant (high warmth/high competence rating compared to other groups), while men occupy the high competence/lower warmth quadrant (Fiske et al., 2002). Gender categories with additional signals may evoke diverse stereotype content. For example, Eckes (2002) finds that career women unlike the category of typical women are perceived to be higher in competence than in warmth. This stands in contrast to the category of typical men, whose perceived warmth/competence is not affected by the career signal.

In terms of ethnicity, the main impetus for focusing on comparing categories Arab and Swedish is that Sweden has recently experienced an influx of immigrants from countries in the Middle East and North Africa (Statistics Sweden, 2019). Previous research shows that male Arab applicants receive fewer callbacks for interviews than male Swedish applicants (Agerström et al., 2012; Carlsson \& Rooth, 2007). We use the Arab generic category to evoke stereotypes associated with this broad group, as it encompasses immigrants into Sweden from several countries. Previous research on the SCM shows that the Arab category is perceived as more competent than warm, although when compared to other groups its scores are situated in the middle of the warmth/competence space (Fiske et al., 2002). One can expect ethnicity to interact in a complex manner with the other included categories.

Both the gay and lesbian categories appear to receive scores in the middle of the warmth/competence space (Fiske et al., 2002). However, according to Brambilla et al. (2011) and Clausell and Fiske (2005), subgroups of these two categories score differently across the warmth/competence space, which suggests that these subgroups contain mixed stereotypes. Clausell and Fiske (2005) propose that the reasoning behind the neutral ratings of the overall categories of gay and lesbian could be that the variety of subgroups contained in these overarching categories cancels each other out, perhaps due to the overall category not being psychologically meaningful. In relation to our study, these findings indicate that if 
combined with other characteristics in a specific context, the homosexual category might receive diverse ratings.

To account for the content of age stereotypes, categories such as "young," "elderly," or "older" have been used in SCM research (e.g., Cuddy et al., 2005). The elderly are typically rated as higher in warmth than in competence, while the young receive mid-scores that do not differentiate on the dimensions. The only research we are aware of that investigates the stereotype content of specific age categories is Krings et al.'s (2011) study, which focuses on 50-year-old workers versus 30-yearold workers. In the current study, we examine the stereotype content of 55-year-old versus 30-year-old workers, as these two age categories are often used in organizational research to distinguish between older and younger employees. For example, field experiments have examined hiring discrimination among employees aged 50,55, and 62 compared to those aged 35 and 40 (Lahey, 2008) and among those aged 49-51 and 64-66 compared to those aged 29-31 (Neumark, Burn, \& Button, 2019) and found evidence of discrimination directed at older workers. Lahey (2008) found that younger workers are $40 \%$ more likely to be invited for an interview, while Neumark et al. (2019) find that middle-aged and older workers respectively receive $18 \%$ and $35 \%$ lower callback rates than younger workers.

Age might interact with other categories in important ways. For example, Carlsson and Eriksson (2019), who submitted 6066 fictitious resumes to vacant low and medium-skilled occupations in Sweden, find that age interacts with gender in regard to the probability of being invited to a job interview. They find that the callback rate for job interviews at age 35 is higher for women than for men but declines faster with age for women.

To summarize, the SCM has not been thoroughly examined with respect to how multiple-group memberships will be perceived in terms of warmth and competence. Furthermore, models of multiple categorization (e.g., the double jeopardy and subordinate-male hypotheses) have not yet been adapted to incorporate warmth and competence stereotypes. Additionally, both the SCM and multiple categorization models have only been sparsely applied to organizational contexts. Thus, rather than prematurely testing formulated predictions, the current exploratory study aims to answer a more general research question:

How do professional workers perceive multiple-group membership or more specifically different combinations of gender, ethnicity, sexual orientation, and age with respect to warmth and competence in the context of work?

\section{Method}

The current study adopts a procedure similar to that used in the investigation of the basic theoretical assumptions of the SCM
(Cuddy et al., 2009; Fiske et al., 2002). The participants were presented with a survey that asked them to rate the perceived warmth and competence of 16 preselected demographic group combinations, which were obtained by combining gender (malelfemale), ethnicity (Arab/Swedish), age (30 vs 55 years of age), and sexual orientation (homosexual/orientation not mentioned). They were instructed to consider general perceptions of these groups in the context of work. Using preselected groups deviates from the most common approach used in the previous literature (Fiske et al., 2002) whereby one group of participants is given questions to generate a list of common groups in society while another sample rates the groups. In addition to rating the groups, the participants in our study were asked to rate the perceived warmth and competence of the most common occupations in Sweden. These occupational data form the empirical basis for a separate study with a different research question.

\section{Stimuli selection strategy}

To simplify the design and focus the investigation on combinations that are of greatest interest, we created 16 groups from combinations of gender, ethnicity, sexual orientation, and age. Generic categories such as only being Swedish were not rated on warmth and competence. Four combinations of ethnicity and gender (Swedish man, Swedish woman, Arab man, and Arab woman) were regarded as reference categories. Eight more combinations of categories were obtained by intersecting the four reference categories with the two age groups (30 and 55 years old; for example, a Swedish man aged 55). The last four categories were obtained by adding homosexual to the four reference categories (for example, $a$ homosexual Swedish man). We did not include any groups that explicitly signaled heterosexual orientation. All stimuli used in the study are listed in Table 1.

Table 1 List of presented social groupings and their intersection

\begin{tabular}{ll}
\hline Group 1 & Group 2 \\
\hline 30-year-old Arab man & Swedish man \\
Swedish woman & Arab woman \\
Arab man & 55-year-old Arab woman \\
Swedish homosexual man & Swedish homosexual woman \\
30-year-old Swedish man & 55-year-old Swedish man \\
55-year-old Arab man & 30-year-old Arab woman \\
Arab homosexual woman & Arab homosexual man \\
55-year-old Swedish woman & 30-year-old Swedish woman \\
\hline
\end{tabular}

Notes: Group 1 corresponds to a set of groups that were rated by one sample of participants, and group 2 corresponds to the second set that was rated by a different sample of participants 
There were several reasons for choosing these 16 combinations and omitting other combinations. First, using the ethnicity and gender intersection as a starting point is common in research addressing hiring discrimination both in the lab and the field (e.g., Bursell, 2014 and Liebkind, Larja, \& Brylka, 2016). In many areas of organizational research and theory, gender and ethnicity (or race) are demographic groups that are often studied together, even when the main aim is focused on differences produced by a specific characteristic. For example, research on hiring discrimination often examines hiring preferences based on ethnicity using stimuli materials that contain only male applicants (e.g., Carlsson \& Rooth, 2007 and Derous, Nguyen, \& Ryan, 2009). It has been considered that these combinations are more relevant for this and future research and should be more informative for perceiver than generic groups. Moreover, research on generic groups such as gender and ethnicity already exists. One can simply return to SCM research on these categories or to different types of experiments to find quite stable perceptions and comparative results. The reason for omitting some combinations is also a practical one, as we wanted to avoid participants with too many similar group combinations to rate.

\section{Survey presentation strategy}

The participants were randomly assigned to one of two fixed versions of the survey, which each contained eight different groups to rate. ${ }^{2}$ There are good arguments for this design. The first argument is related to the fact that we use combined groups, which distinguishes our approach from other closely related studies. With fixed versions, we were able to ensure in the design that the rated groups had similar points of reference. In contrast, if we were to randomly assign combined groups to be rated, some participants could receive very similar groups to rate (e.g., a 30-yearold Arab woman and a 30-year-old Arab man). This could affect ratings given to more dissimilar groups (e.g., a Swedish homosexual man). The second argument is that splitting the groups can avoid arousing suspicion among the participants about the purpose of the study. Our aimto see how combinations of these groups are perceived along the warmth/competence dimensions - would likely be more conspicuous if all group combinations were visible to each participant. The last argument for using fixed versions with only half of the groups is that it makes the survey shorter. This is important since a long survey could

\footnotetext{
2 This followed a similar procedure to Fiske et al.'s (2002). They argue that since the primary focus of the analysis lies at the group level, the results should not be affected by the fact that all groups are not rated by the same participants. Although the analysis conducted in this study differs from a more traditional approach to SCM group ratings, it was still deemed appropriate to split the groups in half.
}

discourage people from participating. We also reversed the order of groups used in the two versions.

\section{Participants}

A professional convenience sample of 133 recruiters and employees of various professional backgrounds participated in the study. Due to the exploratory nature of the current study, we aimed to have a sample size roughly that of the original SCM studies reported in Fiske et al. (2002). Two main methods of data collection were used: a web-based survey and a face-to-face approach involving a pen-and-paper survey. The online survey was accessed 149 times. In total, 115 responses were completed, ${ }^{3}$ which means that $77 \%$ of the participants who accessed the survey completed it. In addition, 19 participants completed the pen-and-paper version of the survey. One participant was excluded because he or she gave the highest scores on virtually all items. No other participants were excluded (e.g., due to how long it took to complete the survey), as there were no other cases for which we had reasons to believe that the participant did not answer the survey questions properly. The final sample thus included 133 participants.

The participants were almost equally assigned to the two versions of the survey and to the order in which the eight combined groups were presented. ${ }^{4}$ The majority were women $(n=87)$, and the average age was $M=41(S D=12.49)$. The ages of the participants range from 21 to 70 years (Table 2).

The survey was targeted at employees involved in making hiring decisions and screening resumes. An alternative approach would have been to target people that specifically have a job position within an HR or recruitment department. However, that would not guarantee that the job involves examining resumes or making hiring decisions, and we could also miss relevant people outside of such departments. Eightynine of the participants reported that they were working as recruiters at the time of the survey; their average work experience in recruitment was $8.79(S D=7.93)$ years with a range of 6 months to 30 years. The remaining 44 participants held positions as managers and CEOs of various types, were employment agency employees, or were other people who satisfied our criteria of being an employee with work experience. Only eight participants stated that they do not have experience working with recruitment (and there were five missing values; see Table 2).

\footnotetext{
3 Twenty-eight accesses contained blank responses, showing that these participants looked at the survey and decided to withdraw. Ten participants did not complete the online survey, six of whom were discarded because they did not complete at least one part.

${ }^{4}$ Sixty-seven participants rated the first version of the survey (regular order: $n=35$; reverse order: $n=32$ ). Sixty-six participants rated the second version of the survey (regular order: $n=32$ and reverse order: $n=34$ ).
} 
Table 2 Participant demographic information

\begin{tabular}{|c|c|c|c|c|c|c|c|c|c|}
\hline \multicolumn{2}{|c|}{ Gender (n) } & \multicolumn{2}{|c|}{$\begin{array}{l}\text { Age } \\
\text { (years) }\end{array}$} & \multicolumn{2}{|c|}{$\begin{array}{l}\text { Do you } \\
\text { work as a } \\
\text { recruiter? }\end{array}$} & \multicolumn{2}{|c|}{$\begin{array}{l}\text { Professional } \\
\text { recruitment } \\
\text { experience } \\
\text { (years) }\end{array}$} & \multicolumn{2}{|c|}{$\begin{array}{l}\text { Recruitment } \\
\text { experience } \\
\text { (self-ratings, } \\
\text { entire } \\
\text { sample) }\end{array}$} \\
\hline Male & Female & 0-30 & 36 & Yes & No & 0-1 & 10 & 1-None & 8 \\
\hline \multirow[t]{5}{*}{41} & 87 & $31-40$ & 24 & 89 & 40 & $2-5$ & 29 & 2 & 14 \\
\hline & & $41-50$ & 35 & & & 6-10 & 11 & 3 & 29 \\
\hline & & $51-60$ & 26 & & & $11-20$ & 26 & 4 & 42 \\
\hline & & $>=60$ & 8 & & & $21-30$ & 5 & 5-Very & 35 \\
\hline & & & & & & & & Much & \\
\hline
\end{tabular}

$\begin{array}{rcccc}\text { Missing: } & & & & \\ 5 & 4 & 4 & 8 & 5 \\ \text { Total } N & & & & 133\end{array}$

\section{Instruments}

Warmth/competence survey The current survey was to a large extent based on that used by Cuddy et al. (2009) to examine the SCM model across cultures. The scale contained: (1) a Warmth subscale with four items on how friendly, warm, well-intentioned and considerate the target groups are perceived to $\mathrm{be}^{5}$ and (2) a Competence subscale with four items on how competent, talented, skillful and ambitious the target groups are perceived to be. ${ }^{6}$ The participants were asked to rate the preselected target groups on a 5-point Likert scale (1 "not at all" to 5 "extremely"). Minor modifications to the original survey were made to fit a Swedish work context. The employed warmth and competence items were largely similar to those used in a previous study on warmth and competence perceptions in the Swedish workplace, where they had demonstrated good psychometric properties (Agerström, 2014). ${ }^{7}$

Demographic characteristics questionnaire The questionnaire also asked for information regarding age, gender, experience in recruitment work, current job roles, place of birth, and the length of residence in Sweden.

\section{Procedure}

A broad sample of participants was targeted, as the main goal was to examine stereotypes present in the workplace on the

\footnotetext{
5 Items in Swedish: "vänlig," "varm," "välmenande," and “omtänksam."

6 Items in Swedish: "kompetent," "begåvad," "skicklig," and "ambitiös."

7 With respect to competence, we used "talented" and "ambitious" instead of "confident" and "capable." With respect to warmth, we used "considerate" instead of "sincere."
}

national level. There were no restrictions on company size, industry, or physical location. The majority of the participants were recruited through email addresses available online on company websites. They received an invitation to participate in the study and a request to share the invitation further within their organizations. Upon agreeing to participate, they received a link to the online version of the survey, for which Qualtrics survey software was used. As a second means to recruit participants, a research assistant visited local businesses in a city in southern Sweden, informed employees about the study, requested their contact information, and then sent the online survey link to those who were interested in participating. The last strategy involved distributing penand-paper surveys at job fairs and professional meetings.

In the cover letter for the survey, the participants were introduced to a study on recruitment processes where they would be asked to rate work-related competencies for various social groups. The participants were explicitly instructed to indicate how the preselected groups are generally perceived in the workplace and not their own personal perceptions. This instruction followed recommendations made by Fiske et al. (2002) for minimizing social desirability.

Due to a low initial response rate, a reward of two movie tickets for completing the study was introduced. The participants were instructed to contact us once the survey was completed to claim their reward. In total, 79 participants claimed their reward.

\section{Analysis approach}

A basic analysis examined some of the statistical characteristics of the SCM, such as the factorial structure, indication of mixed stereotype content, and internal consistency of the scales. The purpose was to examine whether statistical characteristics similar to those of previous SCM research could be found even though the rated groups were preselected, combined, and set in a work context. This was followed by a descriptive analysis of the sample, calculations of interrater agreement, and calculations of mean scores and confidence intervals to find differences between the groups. A multiple regression analysis with interaction terms was employed to investigate how interactions of ethnicity, gender, age, and sexual orientation predict differences in warmth and competence ratings. Given the research design, two types of three-way interactions were analyzed: (1) ethnicity $\times$ gender $\times$ sexual orientation and (2) ethnicity $\times$ gender $\times$ age.

\section{Results}

\section{Basic analysis}

For 15 out of 16 groups, a clear two-factor solution was found. The eigenvalues for the two-factor solutions are larger than 1 
and explained by 54 to $68 \%$ of the total variance. The Swedish woman group is the only category without a two-factor solution, and only one factor with an eigenvalue of greater than 1 was identified. The second factor has an eigenvalue of .96, and with less strict criteria, two factors emerged. Cronbach's alpha values for warmth scales range from .71 to .88 and from .78 to .93 for competence scales. The Cronbach's alpha for the entire sample is .84 for the warmth scale and .89 for the competence scale.

Warmth and competence ratings for each group were created by averaging the four items of each subscale into one mean score for warmth and competence, respectively. All groups generated mean scores close to the middle of the scale. The competence score shows more diversification between the groups with mean scores ranging from 2.74 to 3.91 while the warmth score ranges from 2.94 to 3.83 . The mean group difference score ranges from -.06 to .83 for warmth and from -.26 to .9 for competence. Mean group difference scores were created by centering the results of both scales in the middle and calculating how much each group rating diverged from 3 . Thus, it can be concluded that the variation in the mean score for each group is relatively limited. Ratings on the warmth/ competence scale are highly dependent on all of the presented groups rated, as they act as potential points of reference, which is why focusing on differences from the midpoint of the employed scale was deemed appropriate. The distributions of warmth and competence scores for the reference groups can be found in the Appendix.

Mixed stereotypes Paired sample $t$-tests were conducted to examine indications of mixed stereotype content for the individual groups (Table 3). Eleven out of sixteen groups show statistically significant differences in their warmth and competence scores, which means that $69 \%$ of the presented group combinations show indications of mixed stereotype content. ${ }^{8}$

\section{Breakdown of warmth and competence scores according to category combinations}

The highest competence rating for the entire sample was given to the Swedish man category $(M=3.91, S D=.67)$ while the lowest rating was found for the 55-year-old Arab woman category $(M=2.74, S D=.94)$. The highest warmth rating was given to Swedish homosexual man $(M=3.83, S D=.54)$ while the lowest warmth rating was given to the 55-year-old Arab

\footnotetext{
$\overline{8}$ This follows a similar approach used in Fiske et al. (2002), as they relied on ttests to find indications of mixed stereotypes, though in the current study we are only testing groups at the individual level and not testing whether they belong to mixed clusters.

${ }^{9}$ A similar approach was employed in Finkelstein, Ryan, and King (2013) and Goldberg, Finkelstein, Perry, and Konrad (2004), where an average deviation index was calculated to examine whether the measured metastereotypes for a particular age group and job perceptions showed sufficient agreement to be included in subsequent analyses.
}

man category $(M=2.94, S D=.63)$. The mean warmth and competence rating for the entire sample of groups is presented in Table 4.

In this study, an average score is used to draw conclusions about variables at the group level or more specifically on the warmth/competence perceptions of 16 group combinations. To ensure sufficient agreement among raters, an estimation of interrater agreement was calculated for each demographic group combination using the average deviation index (Burke \& Dunlap, 2002; Burke, Finkelstein, \& Dusig, 1999). ${ }^{9}$ This index is calculated by summing each rater's absolute deviation from the mean rating for an item and dividing it by the number of deviations. We have followed the procedure to calculate the absolute average deviation of individual ratings from the mean rating on both subscales separately for each group combination. We relied on the upper limit value proposed by Burke and Dunlap (2002), which is .83 for a 5-point Likert scale. The results indicate that only one out of 16 group combinations (55-year-old Arab woman) shows a borderline $\mathrm{AD}_{\mathrm{M}}$ of 0.831 (Table 4). As this is an exploratory study and the group in question has to our knowledge not received much empirical attention with respect to stereotype content, it was retained in the main analysis.

Reference categories Mean competence scores for the Arab woman, Arab man, Swedish woman, and Swedish man categories (the reference groups) are presented in Fig. 1 together with $95 \%$ confidence intervals. The results show that the Swedish man category received the highest score on competence $(M=3.91, S E=.08)$ and that Arab woman category received the lowest score $(M=3.00 S E=.10) .{ }^{10}$ The Swedish man category is followed by the Swedish woman $(M=3.67$, $S E=.07)$ and Arab man categories $(M=3.32, S E=.08)$, which received higher competency ratings than Arab woman category. The nonoverlapping confidence intervals show that the Arab man and woman categories have significantly lower scores than the Swedish man and woman categories. The gender differences are much smaller.

The Swedish woman category received the highest warmth score $(M=3.68, S E=.06)$ while Arab man category $(M=$ $2.96, S E=.07)$ has the lowest warmth score. Figure 2 shows the mean warmth score for the four reference groups together with $95 \%$ confidence intervals. A woman has a significantly higher score on warmth compared to a man of the same ethnic group. Interestingly, the Arab woman $(M=3.27, S E=.08)$ and Swedish man $(M=3.20, S E=.07)$ categories receive similar ratings with the confidence intervals overlapping. These results suggest that depending on the reference category combination, ratings on one compared to the other dimension

\footnotetext{
${ }^{10} \mathrm{SE}$ is reported in this section and not $\mathrm{SD}$, as we are presenting and referring to plots that show $95 \%$ confidence intervals, which are calculated from the SE of the mean score.
} 
Table 3 Matched pair $t$-test comparing warmth and competence for individual groups

\begin{tabular}{lcll}
\hline Group & $\begin{array}{l}\text { Mean paired differences } \\
\text { (warmth-competence rating) }\end{array}$ & $\boldsymbol{t}$ & $\boldsymbol{p}$ \\
\hline 30-year-old Arab woman & .044 & $t(65)=0.48$ & .632 \\
30-year-old Arab man & -.414 & $t(66)=-5.75$ & .000 \\
30-year-old Swedish woman & -.096 & $t(65)=-1.29$ & .203 \\
30-year-old Swedish man & -.496 & $t(66)=-6.54$ & .000 \\
55-year-old Arab woman & .418 & $t(65)=4.09$ & .000 \\
55-year-old Arab man & -.250 & $t(66)=-3.04$ & .003 \\
55-year-old Swedish woman & .325 & $t(66)=4.18$ & .000 \\
55-year-old Swedish man & -.783 & $t(65)=-7.41$ & .000 \\
Arab homosexual woman & .082 & $t(66)=1.12$ & .267 \\
Arab homosexual man & .111 & $t(65)=1.49$ & .142 \\
Arab woman & .273 & $t(65)=3.39$ & .001 \\
Arab man & -.362 & $t(66)=-4.73$ & .000 \\
Swedish homosexual man & .231 & $t(66)=3.12$ & .003 \\
Swedish homosexual woman & -.303 & $t(65)=-4.39$ & .000 \\
Swedish woman & .011 & $t(66)=0.21$ & .837 \\
Swedish man & -.705 & $t(65)=-7.02$ & .000 \\
\hline
\end{tabular}

vary, with ethnicity producing larger differences for competence and gender producing larger differences for warmth.

Intersection with sexual orientation The addition of the homosexual orientation signal resulted in a higher competence rating for the Arab homosexual woman category $(M=3.44, S E=.08)$ compared to its reference group. The addition of the signal of homosexuality to the
Swedish man category resulted in a lower competence rating $(M=3.60, S E=.07)$. Similar ratings were found for the Swedish homosexual woman $(M=3.58, S E=.07)$ and Arab homosexual man categories $(M=3.22, S E=.09)$ relative to their respective reference groups. A graphical representation of the groups and their 95\% confidence intervals can be found in Fig. 3 for competence and in Fig. 4 for warmth.
Table 4 Mean scores and $\mathrm{AD}_{\mathrm{M}}$ of warmth and competence for group combinations

\begin{tabular}{lllllll}
\hline & Warmth & $A D_{M}$ & SD & Competence & $A D_{M}$ & SD \\
\hline Reference categories & & & & & & \\
$\quad$ Swedish man & 3.20 & .572 & .60 & 3.91 & .628 & .67 \\
$\quad$ Swedish woman & 3.68 & .557 & .51 & 3.67 & .562 & .54 \\
Arab man & 2.96 & .557 & .57 & 3.32 & .622 & .62 \\
$\quad$ Arab woman & 3.27 & .610 & .62 & 3.00 & .693 & .84 \\
Intersection with age & & & & & & \\
30-year-old Swedish man & 3.23 & .556 & .55 & 3.73 & .627 & .64 \\
55-year-old Swedish man & 3.04 & .618 & .61 & 3.82 & .656 & .69 \\
30-year-old Swedish woman & 3.61 & .668 & .69 & 3.71 & .624 & .60 \\
55-year-old Swedish woman & 3.76 & .592 & .62 & 3.44 & .636 & .58 \\
30-year-old Arab man & 2.99 & .588 & .63 & 3.41 & .600 & .58 \\
55-year-old Arab man & 2.94 & .594 & .63 & 3.19 & .573 & .60 \\
30-year-old Arab woman & 3.30 & .617 & .63 & 3.25 & .690 & .78 \\
55-year-old Arab woman & 3.16 & .665 & .73 & 2.74 & .831 & .94 \\
Intersection with sexual orientation \\
$\quad$ & & & & & & .604 \\
Swedish homosexual man & 3.83 & .535 & .54 & 3.60 & .56 \\
Swedish homosexual woman & 3.28 & .589 & .56 & 3.58 & .682 & .76 \\
Arab homosexual man & 3.33 & .685 & .68 & 3.22 & 0.626 & .64 \\
Arab homosexual woman & 3.53 & .667 & .66 & 3.44 & & .60 \\
\hline
\end{tabular}




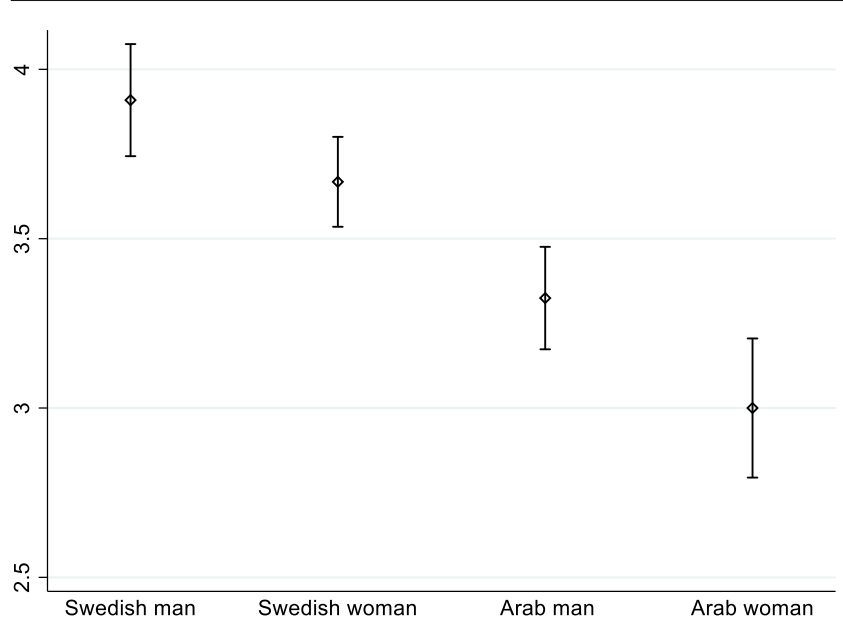

Fig. 1 Mean competence ratings of reference groups. Note: $95 \%$ confidence intervals

The warmth score is affected by the signal of homosexual orientation, which created higher ratings for the Arab homosexual woman $(M=3.53, S E=.08)$, Arab homosexual man $(M=3.33, S E=.08)$, and Swedish homosexual man categories $(M=3.83, S E=.07)$, but a lower warmth score for Swedish homosexual woman category $(M=3.28, S E=.07)$.

Intersection with age The perceived competence ratings for the Swedish man and Arab man categories remain similar with the addition of age as a category. The Swedish woman category $(M=3.67, S E=.07)$ has similar ratings for all category combinations with age on both dimensions, except that the competence score is lower for the 55-year-old Swedish woman category $(M=3.44, S E=.07)$. The addition of the 55-year-old age group category to the Arab woman category lowered competence $(M=2.74, S E=.12)$ compared to the reference group $(M=3.00, S E=.10)$ while the addition of the 30-year-old age group category increased the competence rating to $M=3.25, S E=.10$. Adding the signal of age did not

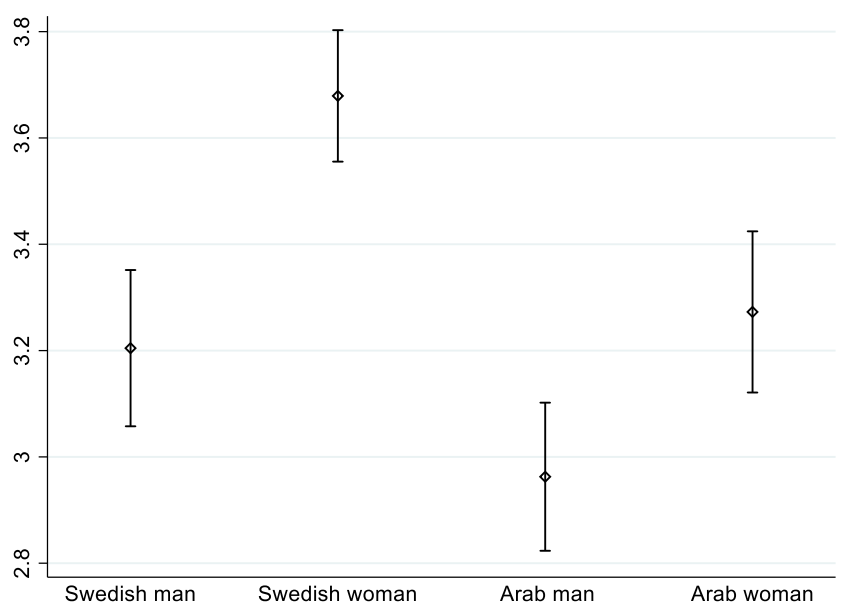

Fig. 2 Mean warmth ratings for reference groups. Note: $95 \%$ confidence intervals substantially change the warmth scores of any of the reference groups. These comparisons refer to the addition of age signals for each reference category separately. Competence scores are graphically depicted in Fig. 5 and warmth scores are illustrated in Fig. 6.

Interaction of ethnicity, gender, and sexual orientation Three categorical variables were created to form the predictors. The ethnicity variable consists of the Swedish and Arab levels, which was created by collapsing all categories containing each signal, while the gender variable contains the male and female levels. The final categorical predictor is sexual orientation, which was created by collapsing all categories with no mention of sexual orientation and those including a homosexual orientation. When a three-way interaction was tested with ethnicity, gender, and sexual orientation, no statistically significant interactions emerged from the competence scores $(t=1.10, p=.275)$ (Table 5).

The three-way interaction of ethnicity, gender, and sexual orientation for warmth scores was found to be significant $(t=3.78, p=.000)$. With the addition of the homosexual orientation signal, perceived warmth increased for Swedish men while the opposite was the case for Swedish women, whose warmth score decreased (Fig. 7). For Arabs, the pattern that emerges differs from perceptions of Swedes. Arab women keep their warmth advantage over Arab men and even experience a small boost in warmth perceptions.

Interaction of ethnicity, gender and age The three-way interaction for ethnicity, gender, and age was not found to be significant with respect to competence when adding the 55 years of age category $(t=-0.73, p=.467)$ nor when adding the 30 years of age category $(t=-1.41, p=.160)$ (Table 6).

However, with respect to warmth, the three-way interaction was found to be significant both when adding the 55 years of age category $(t=-4.63, p=.000)$ and when adding the 30 years of age category $(t=-2.47, p=.015)$. For 55-year-old Swedish women, the perception of warmth was higher than for 30-year-old Swedish women. The opposite is true for Arab women, with 30-year-olds being perceived as higher in warmth than 55-year-olds (Fig. 8).

\section{Discussion}

In this study, we have investigated how combinations of common group memberships influence warmth and competence perceptions, and, to our knowledge, it is the first study to apply the SCM to multiple-group membership in a 
Fig. 3 Mean competence rating for intersection with sexual orientation. Note: $95 \%$ confidence intervals

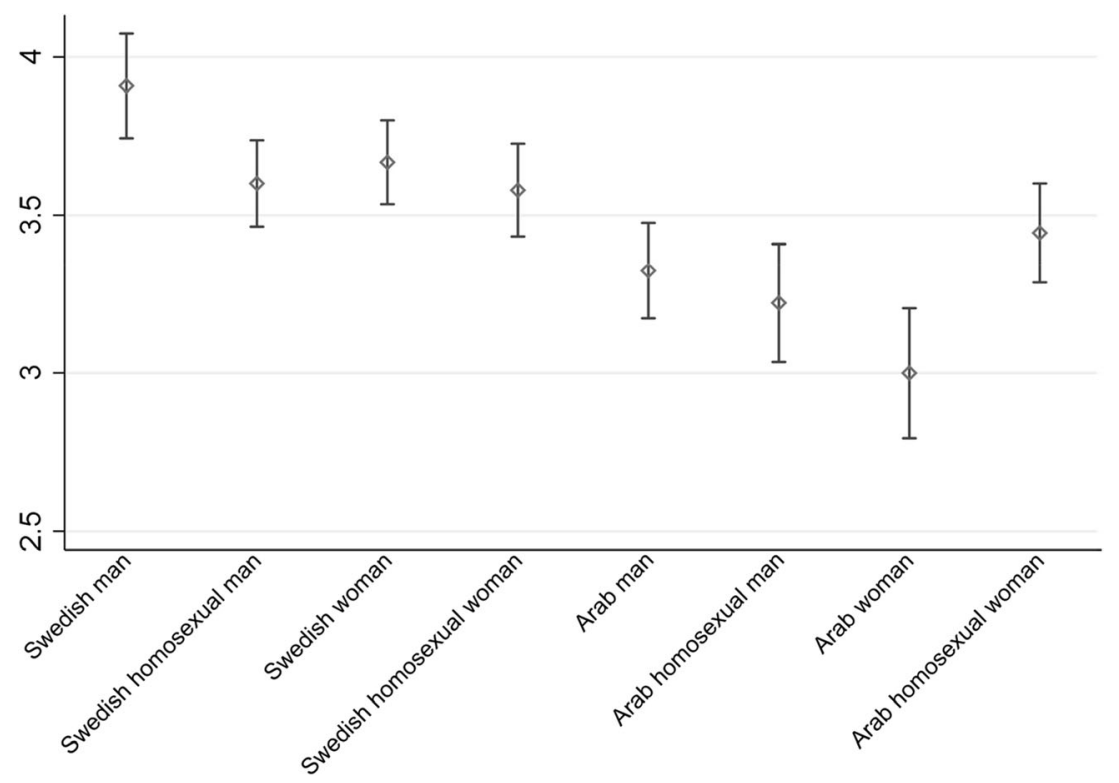

work context. The findings relating to statistical characteristics usually present in SCM research are similar and in line with previous findings (Fiske et al., 2002). This similarity suggests the usefulness of examining intersections of specifically preselected groups in a work context. The findings also shed light on unique stereotype content emerging from employees' perceptions of these previously unexplored demographic group combinations. For some reference categories, no evidence of different ratings on warmth and competence were found, while their intersections indicate mixed stereotypes. For example, for the Swedish woman category we found no indication of mixed stereotypes, but the Swedish homosexual woman category was rated higher on competence than warmth. This finding supports our argument that characteristics other than ethnicity and gender such as sexual orientation matter and have important intersectional qualities that influence warmth and competence perceptions.

An interesting finding of the current study is that warmth and competence perceptions vary in sensitivity depending on which categories are intersected. In relation to the reference categories, gender seems to be especially important for warmth, whereas ethnicity seems to be particularly important for competence perceptions. This has implications for selection decisions. When ethnicity is being intersected, recruiters may focus on competence-related qualities, whereas when gender is being intersected, they may focus on warmth qualities (e.g., empathy skills).
Fig. 4 Mean warmth rating for intersection with sexual orientation. Note: $95 \%$ confidence intervals

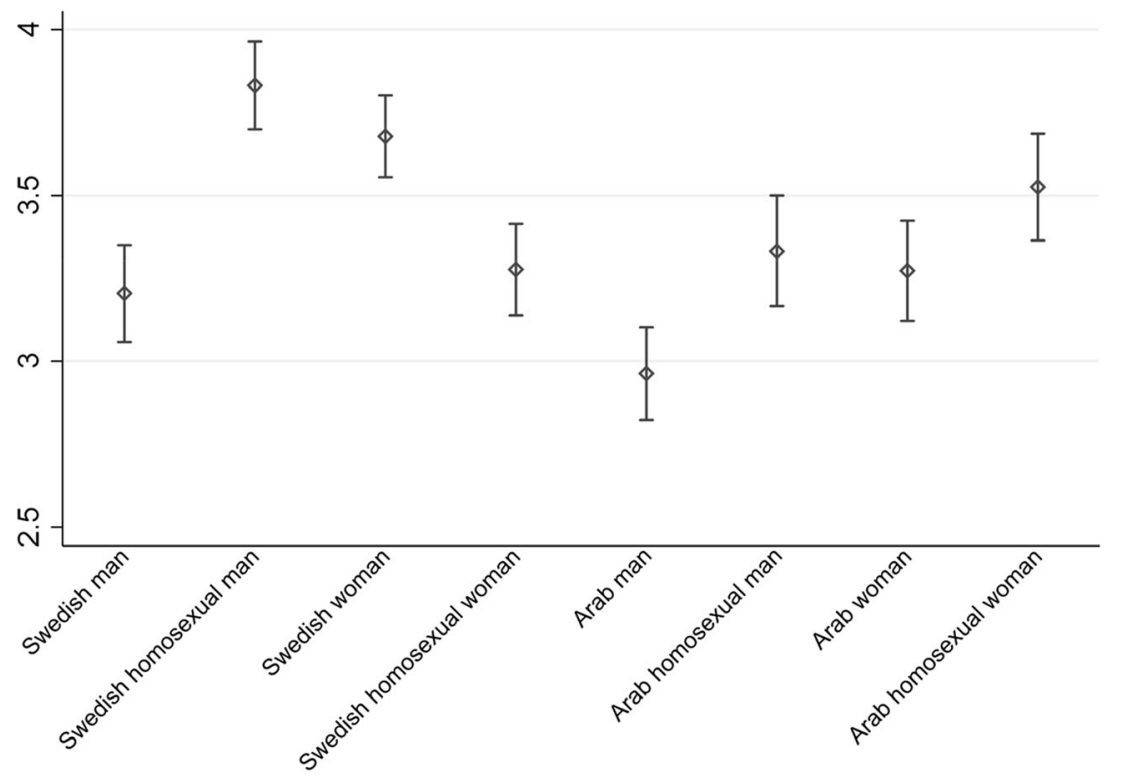


Fig. 5 Mean competence rating for intersection with age. Note: $95 \%$ confidence intervals

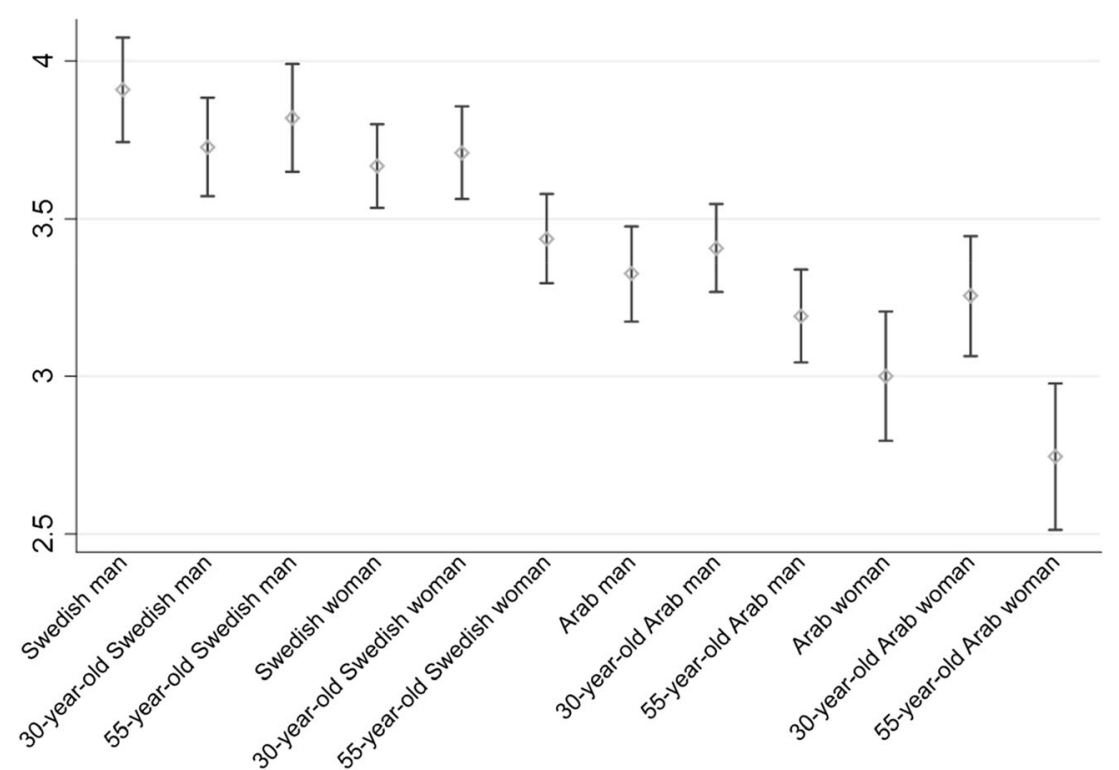

The addition of the age signal showed that 55-year-old Swedish women received higher warmth scores than 30year-old Swedish women, while the opposite pattern was observed for Arab women. The latter finding is interesting in light of previous research, which usually finds that the young category lowers perceived warmth compared to the elderly category. Our finding that Arab women's perceived warmth is boosted when young age is introduced contributes to previous work by showing that the introduction of a new category (here ethnicity) has the potential to fundamentally change the direction of previously established effects of age on perceived warmth.

The results of the regression analysis suggest that warmth ratings were more responsive to the homosexuality signal. The Swedish homosexual man category resulted in stereotypes similar to the more general man category described in traditional SCM research, with a drop in competence and a boost in warmth (Fiske et al., 2002). In comparison, the Arab men reference category received an increase in warmth while perceived competence remained somewhat intact when the homosexuality signal was added. This boost may have implications for Arab job applicants considering that research has found that when male Arab applicants signal both warmth and competence, this increases their callback rates for job interviews in the real labor market (Agerström et al., 2012). Previous research shows that the addition of a homosexuality signal can result in women being perceived more like men by receiving a boost in competence and a decline in warmth (Fiske et al., 2002). Interestingly, we find that Arab women
Fig. 6 Mean warmth ratings for intersection with age. Note: $95 \%$ confidence intervals

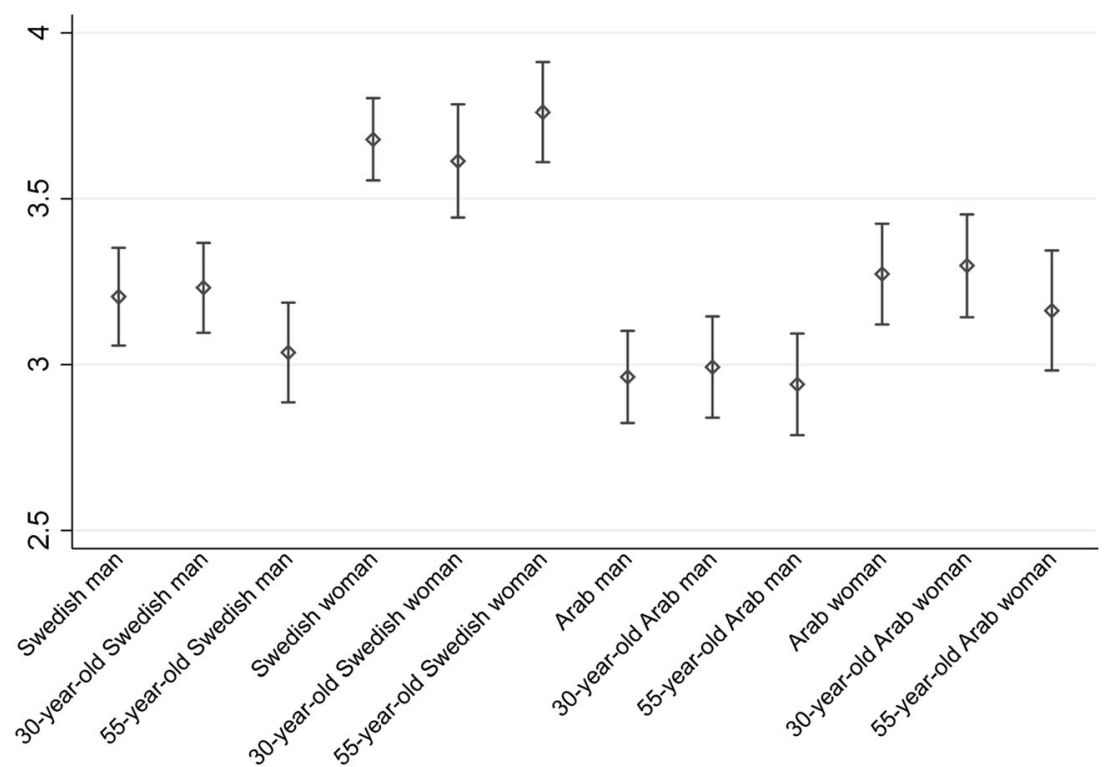


Table 5 Competence and warmth scores for the reference groups and sexual orientation

\begin{tabular}{lcl}
\hline & Competence & Warmth \\
& $B$ & $B$ \\
\hline Constant (Swedish man) & $3.82^{* * *}$ & $3.16^{* * *}$ \\
& $(.059)$ & $(.051)$ \\
Homosexual orientation & $-.22^{* * *}$ & $.67 * * *$ \\
& $(.080)$ & $(.077)$ \\
Woman & $-.21 * * *$ & $.53^{* * *}$ \\
& $(.058)$ & $(.062)$ \\
Woman $\times$ homosexual orientation & .19 & $-1.08^{* * *}$ \\
& $(.124)$ & $(.128)$ \\
Arab & $-.51 * * *$ & $-.19^{* * *}$ \\
& $(.087)$ & $(.079)$ \\
Arab $\times$ homosexual orientation & .13 & $-.31^{* *}$ \\
& $(.156)$ & $(.142)$ \\
Arab $\times$ woman & -.09 & $-.25^{* *}$ \\
& $(.131)$ & $(.111)$ \\
Arab $\times$ woman $\times$ homosexual orientation & .34 & $1.00^{* * *}$ \\
& $(.307)$ & $(.264)$ \\
\hline
\end{tabular}

Notes: $N=1064$ (no. of ratings). The regression includes no additional covariates. Standard errors (in parentheses) are clustered by respondent to account for that each participant rates multiple combined groups. ***Significant at the $1 \%$ level, **significant at the $5 \%$ level; *significant at the $10 \%$ level

receive a boost in both perceived warmth and competence when the homosexuality signal is added. Specifically, Arab applicants may benefit from disclosing homosexuality in hiring contexts, as homosexual Arab individuals were perceived more positively than heterosexual Arab individuals, especially with respect to warmth perceptions. Relatedly, a recent study finds that when Black, Hispanic, and Asian minority men signal homosexuality, they are perceived as less stereotypic of their own racial/ethnic group (Petsko \& Bodenhausen, 2019). This "de-racialization" may at least partly explain our results for Arabs. The boost in warmth found for Arab men and the boost in both warmth and competence found for Arab women when both groups were also described as homosexual may have to do with homosexuality causing them to be perceived as less stereotypic of their own ethnic group.

The finding that Arab women seem to benefit even more than Arab men, showing an increase in both perceived warmth and competence when also depicted as homosexual, is interesting. It may be that it is more unusual to encounter Arab women than Arab men in the Swedish labor market. When homosexuality is also signaled, this contributes further to the perceived unexpectedness, as homosexuality conflicts with the general Arab stereotype. This high unexpectedness could be responsible for the increased ratings with respect to both dimensions. This interpretation is consistent with the "de-racialization" hypothesis (Petsko \& Bodenhausen, 2019), as Arab women who are both employed and homosexual should be perceived as highly

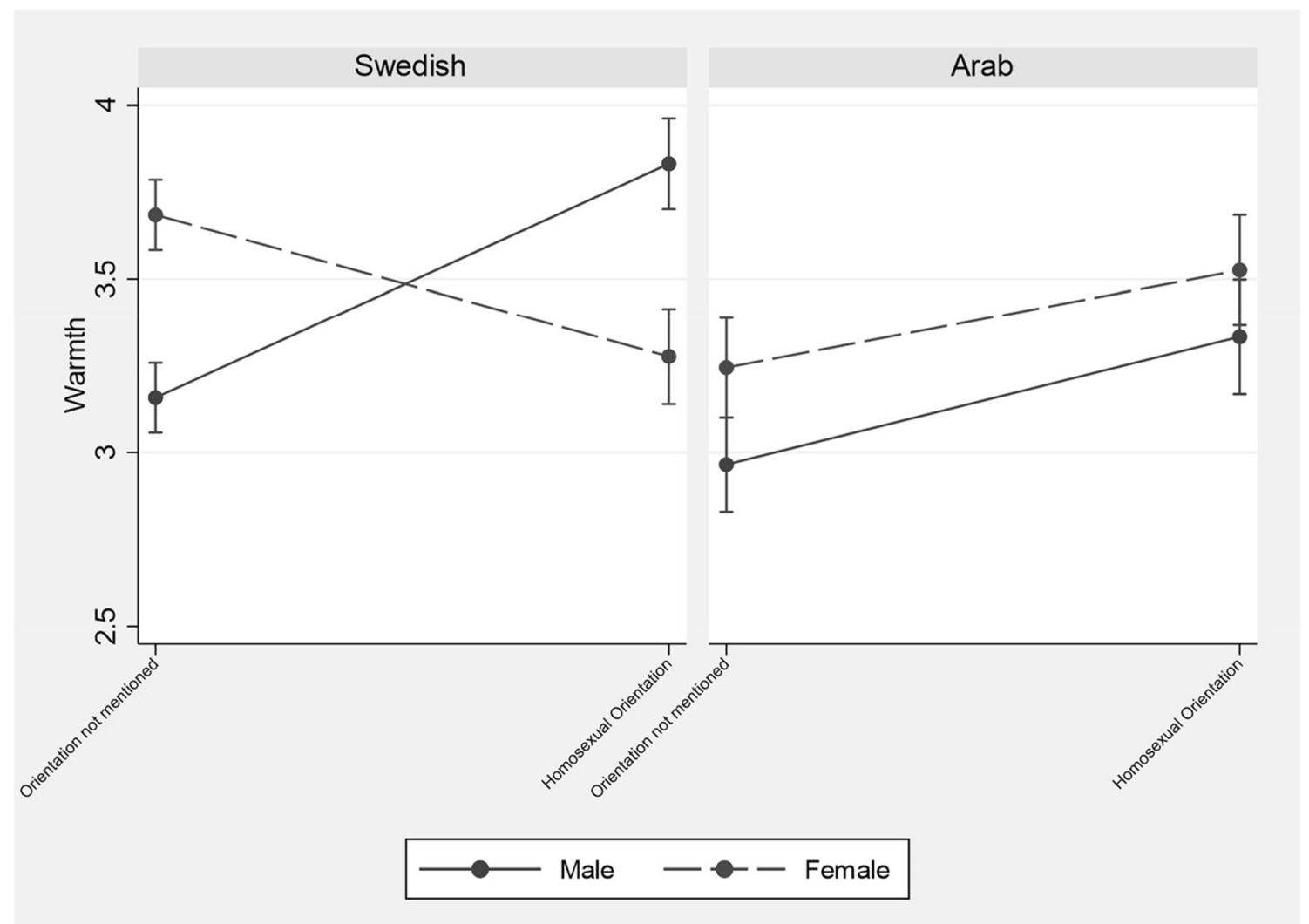

Fig. 7 Ethnicity, gender, sexual orientation — interaction plots for warmth. Note: 95\% confidence interval 
Table 6 Competence and warmth scores for the reference groups, and ages 30 and 55

\begin{tabular}{|c|c|c|}
\hline & $\begin{array}{c}\text { Competence } \\
B\end{array}$ & $\begin{array}{c}\text { Warmth } \\
B\end{array}$ \\
\hline Constant (Swedish man) & $\begin{array}{l}3.75^{* * * *} \\
(.055)\end{array}$ & $\begin{array}{l}3.52 * * * \\
(.057)\end{array}$ \\
\hline Age 30 & $\begin{array}{l}-.03 \\
(.080)\end{array}$ & $\begin{array}{l}-.29 * * * \\
(.080)\end{array}$ \\
\hline Age 55 & $\begin{array}{l}.07 \\
(.070)\end{array}$ & $\begin{array}{l}-.48 * * * \\
(.072)\end{array}$ \\
\hline Woman & $\begin{array}{l}-.13 * * \\
(.053)\end{array}$ & $\begin{array}{l}-.04 \\
(.048)\end{array}$ \\
\hline Woman $\times$ age 30 & $\begin{array}{l}.11 \\
(.122)\end{array}$ & $\begin{array}{l}.42 * * * \\
(.126)\end{array}$ \\
\hline Woman $\times$ age 55 & $\begin{array}{l}-.25 * * \\
(.105)\end{array}$ & $\begin{array}{l}.77 * * * \\
(.103)\end{array}$ \\
\hline Arab & $\begin{array}{l}-.48^{* * * *} \\
(.072)\end{array}$ & $\begin{array}{l}-.37 * * * \\
(.079)\end{array}$ \\
\hline Arab $\times$ age 30 & $\begin{array}{l}.16 \\
(.099)\end{array}$ & $\begin{array}{l}.14 \\
(.099)\end{array}$ \\
\hline Arab $\times$ age 55 & $\begin{array}{l}-.15 \\
(.098)\end{array}$ & $\begin{array}{l}.28 * * \\
(.106)\end{array}$ \\
\hline Arab $\times$ woman & $\begin{array}{l}.08 \\
(.066)\end{array}$ & $\begin{array}{l}.30^{* * * *} \\
(.081)\end{array}$ \\
\hline Arab $\times$ woman $\times$ age 30 & $\begin{array}{l}-.21 \\
(.151)\end{array}$ & $\begin{array}{l}-.37 * * \\
(.150)\end{array}$ \\
\hline Arab $\times$ woman $\times$ age 55 & $\begin{array}{l}-.14 \\
(.194)\end{array}$ & $\begin{array}{l}-.80 * * * * \\
(.172)\end{array}$ \\
\hline
\end{tabular}

Notes: $N=1064$ (no. of ratings). The regression includes no additional covariates. Standard errors (in parentheses) are clustered by respondent to account for that each participant rates multiple combined groups. ***Significant at the $1 \%$ level, **significant at the $5 \%$ level; *significant at the $10 \%$ level

nonstereotypic of Arab women as a general group. Clearly, more research examining how sexual orientation changes people's stereotypical perceptions of different ethnic minority groups is needed. Our findings suggest that such research should focus on ethnic minority women in particular to extend our understanding of how sexual orientation shapes people's perceptions of this relatively unexplored social group.

Although the main models of multiple-group membership in organizational contexts have little to say about warmth and competence perceptions as such, we will attempt to interpret some of our results in relation to these models. In relation to the double jeopardy hypothesis, one may expect that Arab homosexual women, due to their membership in what could be seen as three societal outgroups, would receive lower ratings on both dimensions, at least compared to their reference group (Arab women). We find, however, that with the addition of the homosexuality category, Arab women receive a boost in perceived warmth and competence. The subordinate-male hypothesis would predict the male category of the minority group to receive the lowest ratings. Our findings are not consistent with the subordinate-male hypothesis because they show, for example, that Arab men are perceived higher on competence than Arab women. It is difficult to translate the ethnic-prominence hypothesis to this context, and although Arabs in general receive lower scores than Swedes, our results show that adding older age lowered the ratings of the Arab woman category to the lowest of the tested group combinations. There is nothing in our data that suggests that age and gender should not be treated on par with ethnicity in the context of multiple categorization, at least when the Arab minority group is concerned.

These results have direct implications for researchers when they set the design for future experimental studies on multiple groups. According to Cuddy et al. (2011), there could be a possible fit between the stereotype content of demographic groups and different types of occupations. Understanding multiple-group membership combinations in terms of warmth and competence could paint a more nuanced picture of the discrimination that people who simultaneously belong to multiple minority groups face in the labor market, and possibly in other contexts as well. The results of this study provide new knowledge on what the stereotype content of multiple-group membership could look like before planning laboratory and field studies on discrimination. For example, since Arab men who are homosexual are seen as warmer than their reference category and seem to retain a similar level of competence, one could predict that in an occupation where warmth is of central importance, Arab homosexual men might receive a boost in how they are perceived and subsequently evaluated in relation to job requirements. If and under which circumstances there is a perceived warmth/competence "fit" between stereotype content at the multiple group level and occupation type are important research questions that should be addressed in future studies.

As Sweden scores high on various measures of equality (European Commission, 2018) and is considered to be an egalitarian country at the forefront of equality and diversity policies, the multiple group differences uncovered in the current research may possibly be smaller than those that might be found in other countries. Compared to the USA, however, the warmth/ competence content of the basic reference categories (ethnicity and gender intersections) observed in our study shows a similar pattern to the single categories reported in the USA by Fiske et al. (2002). This suggests that our results may be applicable to a US context, though we note that the stereotype content of multiplegroup membership may be qualitatively different than that for single groups.

\section{Limitations}

Some of the limitations of the study concern the choice of stimuli. We are unable to determine whether combining groups could move the specific combination to a different 


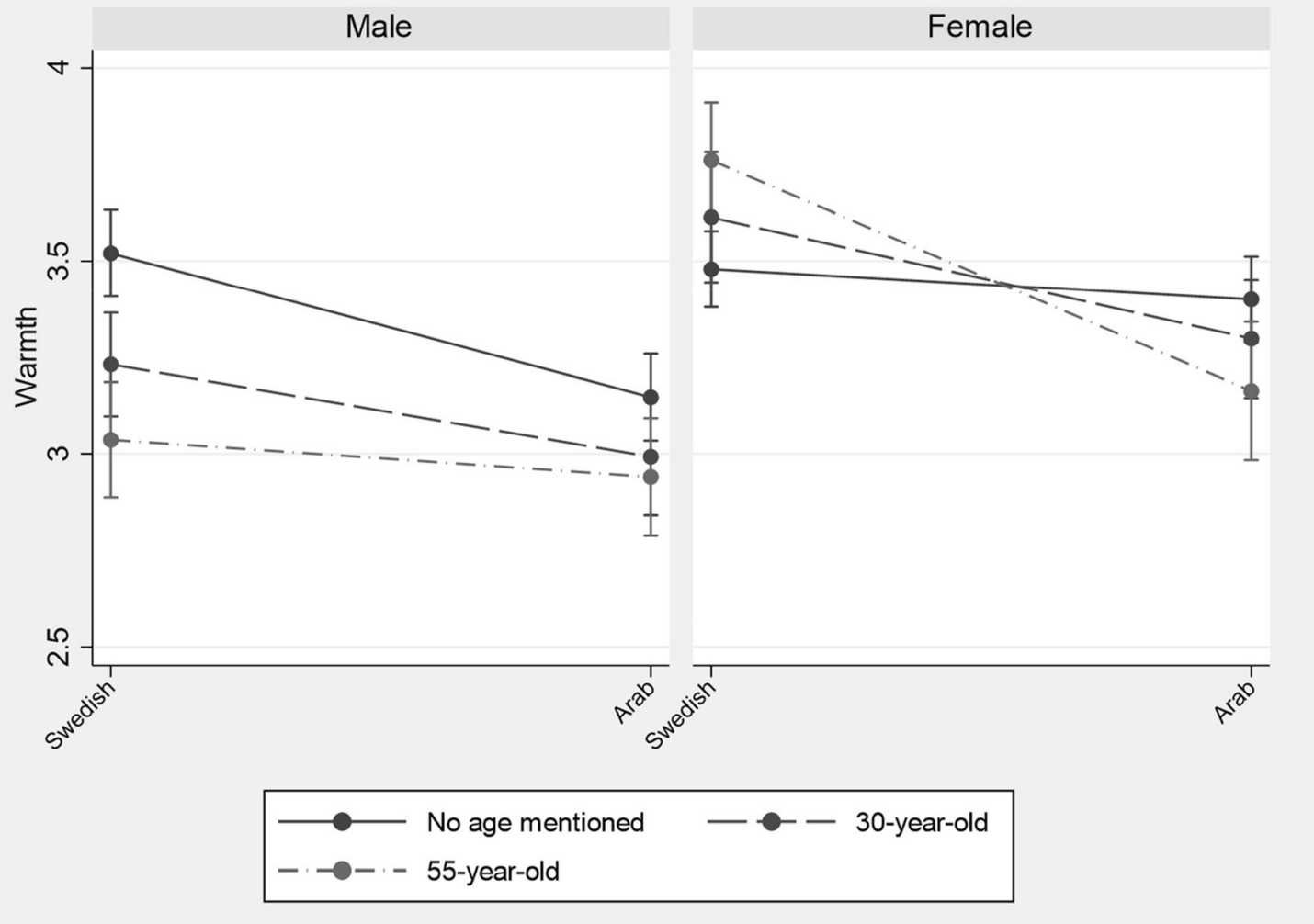

Fig. 8 Ethnicity, gender, age — interaction plot for warmth. Note: 95\% confidence interval

quadrant of the warmth/competence space. The reason for this is that other groups relevant for SCM research (e.g., the homeless and elderly people), which could serve as a reference and disperse the groups further, were not included. The current design only allowed us to compare the chosen groups and to examine how warmth/competence perceptions could change with the addition of categories.

As this was an exploratory study, we did not formulate and explicitly test specific predictions. Thus, further corroboration of the findings is needed. We contend that such research is conducive to the development of more refined theoretical models that can accommodate a larger number of intersected categories.

Following the typical SCM approach (e.g., Fiske et al., 2002), our research participants were not asked about their own perceptions, but rather how they believe the groups are generally perceived in the workplace. The main impetus for measuring culturally shared, as opposed to personal, stereotypes was to minimize social desirability concerns. One limitation of this approach is that we cannot be certain that our participants' beliefs accurately reflect stereotypes operating in the workplace, even if previous research has found that people show high levels of agreement in their reports of cultural stereotypes, even cross-culturally (e.g., Cuddy et al., 2009; Fiske et al., 2002). Future research should examine to what extent the cultural stereotypes of the studied group combinations actually operate in the workplace.

\section{Concluding remarks}

The current study contributes to the relatively limited research literature on multiple categorization by shedding light on how previously unexplored combinations of social categories influence warmth and competence perceptions in the context of the workplace. We conclude that when one or two categories intersect with another category, warmth and competence perceptions can be influenced in a complex way that does not make algebraic sense. Rather, as our results on the positive impact of signaling homosexuality for the Arab ethnic minority group suggest, one category perceived negatively in isolation may offset the negative impact of another stigmatized category. Even more, when these groups are also intersected with gender, adding female gender seems to boost perceived competence, which is interesting in light of previous "single category" work showing that women tend to be stereotyped as lower on competence than males (Heilman, 2012). Finally, we hope that the current study will spur more work on multiple categorization based on warmth and competence and that it will provide additional guidance to researchers who want to develop and test informed predictions on how such categories combine and influence stereotypical perceptions in the workplace.

Acknowledgements Open access funding provided by Linnaeus University. 
Authors' contributions Andrea Strinić conceived and designed the study, collected and analyzed the data, and drafted the paper. Magnus Carlsson and Jens Agerström made substantial contributions to the conception and design of the study, data analysis, and revised the paper for important intellectual content.

Funding information This research was supported by the Swedish Research Council (Grant no. 2018-03487).

Data availability The datasets generated and analyzed during the current study are available from the corresponding author on request.

\section{Compliance with ethical standards}

Conflict of interest The authors declare that they have no conflict of interest.

Ethical considerations The study did not include collecting any potentially identifying or sensitive information, and it relied on publicly available information to contact participants. Debriefing was either provided in oral form or written after completing an online questionnaire.

\section{Appendix}

Fig. 9 Distribution of competence ratings for reference groups (used in regression)
Fig. 10 Distribution of warmth ratings for reference groups (used in regression)
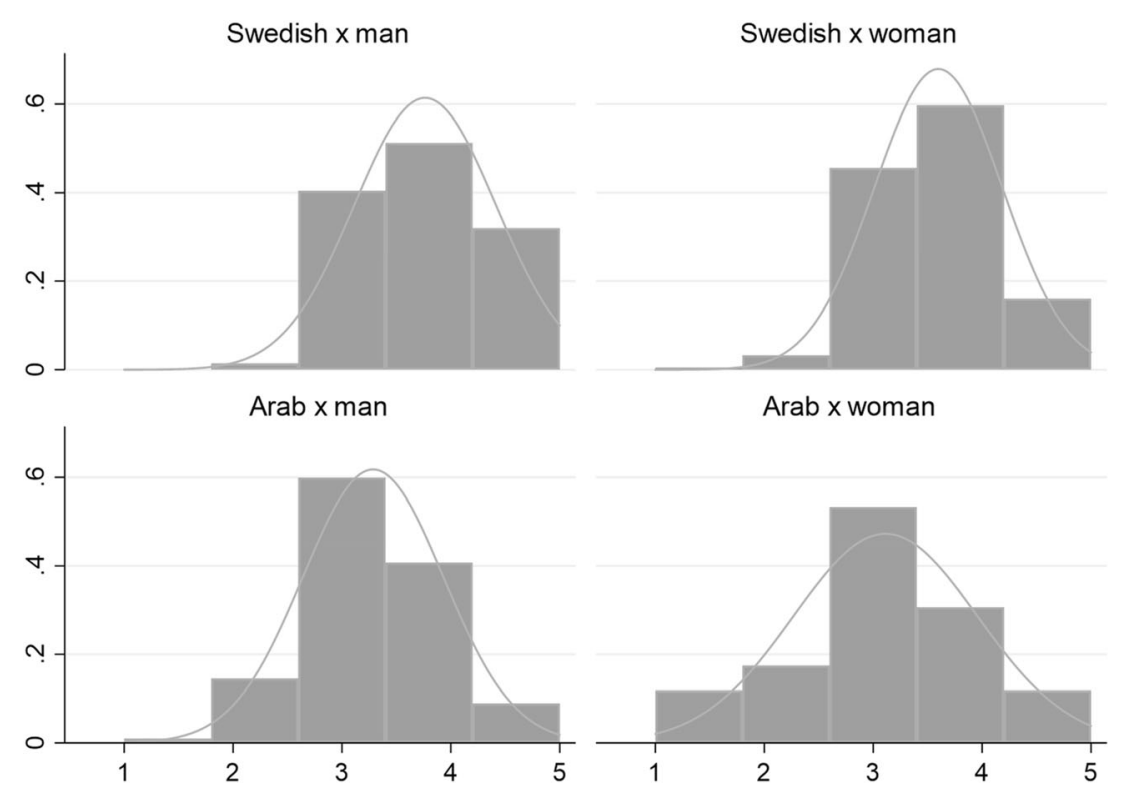
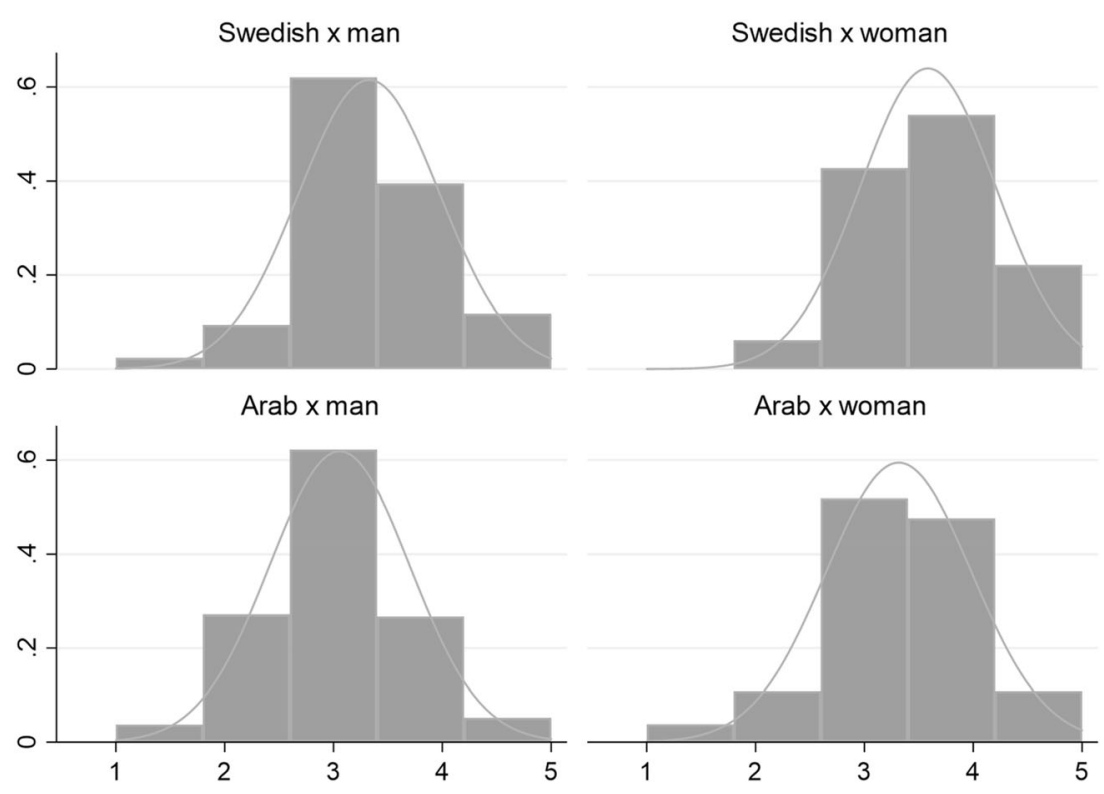
Fig. 11 Distribution of competence ratings for reference groups (simple categories)
Swedish man
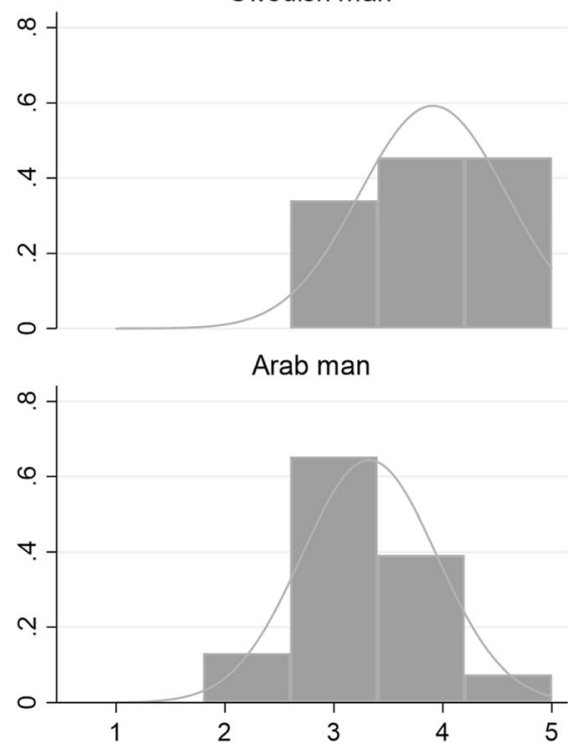

Swedish woman

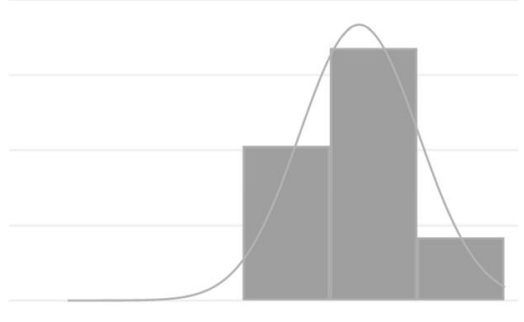

Arab woman

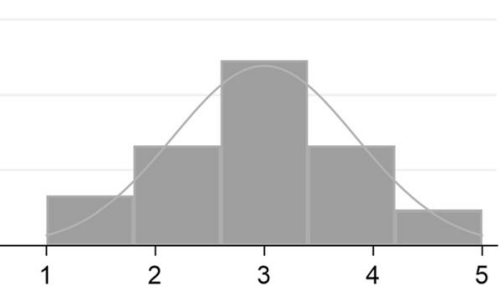

Fig. 12 Distribution of warmth ratings for reference groups (simple categories)

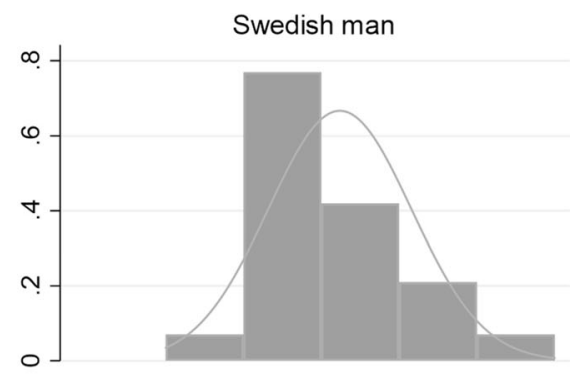

Arab man

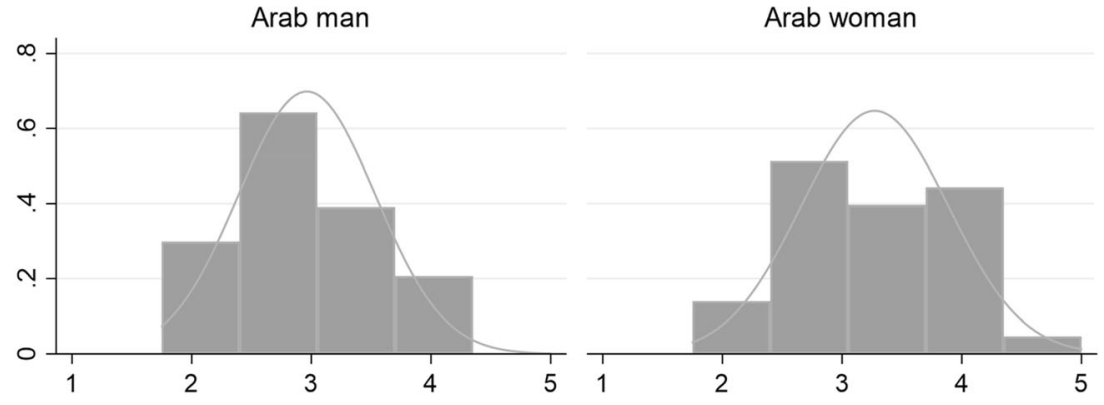


Open Access This article is licensed under a Creative Commons Attribution 4.0 International License, which permits use, sharing, adaptation, distribution and reproduction in any medium or format, as long as you give appropriate credit to the original author(s) and the source, provide a link to the Creative Commons licence, and indicate if changes were made. The images or other third party material in this article are included in the article's Creative Commons licence, unless indicated otherwise in a credit line to the material. If material is not included in the article's Creative Commons licence and your intended use is not permitted by statutory regulation or exceeds the permitted use, you will need to obtain permission directly from the copyright holder. To view a copy of this licence, visit http://creativecommons.org/licenses/by/4.0/.

\section{References}

Abele, A. E., Hauke, N., Peters, K., Louvet, E., Szymkow, A., \& Duan, Y. (2016). Facets of the fundamental content dimensions: Agency with competence and assertiveness - communion with warmth and morality. Frontiers in Psychology, 7, 1810. https://doi.org/10.3389/ fpsyg.2016.01810.

Abele, A. E., \& Wojciszke, B. (2018). Introduction: The big two of agency and communion as an overarching framework in psychology. In A. E. Abele \& B. Wojciszke (Eds.), Agency and Communion in Social Psychology (pp. 1-12). London: Routledge. https://doi. org/10.4324/9780203703663.

Agerström, J. (2014). Why does height matter in hiring? Journal of Behavioral and Experimental Economics, 52, 35-38. https://doi. org/10.1016/j.socec.2014.06.002.

Agerström, J., Björklund, F., Carlsson, R., \& Rooth, D. O. (2012). Warm and competent Hassan $=$ cold and incompetent Eric: A harsh equation of real-life hiring discrimination. Basic and Applied Social Psychology, 34(4), 359-366. https://doi.org/10.1080/01973533. 2012.693438.

Beale, F. (1970). Double jeopardy: To be Black and female. In T. Cade (Ed.), The Black woman (pp. 109-122). New York, NY: New American Library.

Bertrand, M., \& Duflo, E. (2017). Field experiments on discrimination. In A. V. Banerjee \& E. Duflo (Eds.), Handbook of Economic Field Experiments (Vol. 1, pp. 309-393). Cambridge: Cambridge University Press. https://doi.org/10.1016/bs.hefe.2016.08.004.

Brambilla, M., Carnaghi, A., \& Ravenna, M. (2011). Status and cooperation shape lesbian stereotypes. Social Psychology, 42(2), 101-110. https://doi.org/10.1027/1864-9335/a000054.

Burke, M. J., \& Dunlap, W. P. (2002). Estimating interrater agreement with the average deviation index: A user's guide. Organizational Research Methods, 5(2), 159-172. https://doi.org/10.1177/ 1094428102005002002.

Burke, M. J., Finkelstein, L. M., \& Dusig, M. S. (1999). On average deviation indices for estimating interrater agreement. Organizational Research Methods, 2(1), 49-68. https://doi.org/10. 1177/109442819921004.

Bursell, M. (2014). The multiple burdens of foreign-named menEvidence from a field experiment on gendered ethnic hiring discrimination in Sweden. European Sociological Review, 30(3), 399-409. https://doi.org/10.1093/esr/jcu047.

Bye, H. H., Herrebrøden, H., Hjetland, G. J., Røyset, G. Ø., \& Westby, L. L. (2014). Stereotypes of Norwegian social groups. Scandinavian Journal of Psychology, 55(5), 469-476. https://doi.org/10.1111/ sjop.12141.

Carlsson, M., \& Eriksson, S. (2019). Age discrimination in hiring decisions: Evidence from a field experiment in the labor market. Labour
Economics, 55, 173-183. https://doi.org/10.1016/j.labeco.2019.03. 002.

Carlsson, M., \& Rooth, D. O. (2007). Evidence of ethnic discrimination in the Swedish labor market using experimental data. Labour Economics, 14(4), 716-729. https://doi.org/10.1016/j.labeco.2007. 05.001 .

Carlsson, R., \& Björklund, F. (2010). Implicit stereotype content : Mixed stereotypes can be measured with the implicit association test. Social Psychology, 41(4), 213-222. https://doi.org/10.1027/1864-9335/ a000029.

Clausell, E., \& Fiske, S. T. (2005). When do subgroup parts add up to the stereotypic whole? Mixed stereotype content for gay male subgroups explains overall ratings. Social Cognition, 23(2), 161-181. https://doi.org/10.1521/soco.23.2.161.65626.

Cuddy, A. J. C., Fiske, S. T., \& Glick, P. (2007). The BIAS map: Behaviors from intergroup affect and stereotypes. Journal of Personality and Social Psychology, 92(4), 631-648. https://doi. org/10.1037/0022-3514.92.4.631.

Cuddy, A. J. C., Fiske, S. T., \& Glick, P. (2008). Warmth and competence as universal dimensions of social perception: The stereotype content model and the BIAS map. In M. P. Zanna (Ed.), Advances in Experimental Social Psychology (Vol. 40, pp. 61-149). New York: Academic Press. https://doi.org/10.1016/S0065-2601(07) 00002-0.

Cuddy, A. J. C., Fiske, S. T., Kwan, V. S. Y., Glick, P., Demoulin, S., Leyens, J.-P., Bond, M. H., Croizet, J. C., Ellemers, N., Sleebos, E., Htun, T. T., Kim, H. J., Maio, G., Perry, J., Petkova, K., Todorov, V., Rodríguez-Bailón, R., Morales, E., Moya, M., Palacios, M., Smith, V., Perez, R., Vala, J., \& Ziegler, R. (2009). Stereotype content model across cultures: Towards universal similarities and some differences. British Journal of Social Psychology, 48(1), 133. https://doi.org/10.1348/014466608X314935.

Cuddy, A. J. C., Glick, P., \& Beninger, A. (2011). The dynamics of warmth and competence judgments, and their outcomes in organizations. Research in Organizational Behavior, 31, 73-98. https:// doi.org/10.1016/j.riob.2011.10.004.

Cuddy, A. J. C., Norton, M. I., \& Fiske, S. T. (2005). This old stereotype: The pervasiveness and persistence of the elderly stereotype. Journal of Social Issues, 61(2), 267-285. https://doi.org/10.1111/j.15404560.2005.00405.x.

Derous, E., Nguyen, H. H., \& Ryan, A. M. (2009). Hiring discrimination against Arab minorities: Interactions between prejudice and job characteristics. Human Performance, 22(4), 297-320. https://doi. org/10.1080/08959280903120261.

Derous, E., Ryan, A. M., \& Nguyen, H. H. D. (2012). Multiple categorization in resume screening: Examining effects on hiring discrimination against Arab applicants in field and lab settings. Journal of Organizational Behavior, 33(4), 544-570. https://doi.org/10.1002/ job.769.

Derous, E., Ryan, A. M., \& Serlie, A. W. (2015). Double jeopardy upon resumé screening: When Achmed is less employable than Aïsha. Personnel Psychology, 68(3), 659-696. https://doi.org/10.1111/ peps. 12078.

Eckes, T. (2002). Paternalistic and envious gender stereotypes : Testing predictions from the stereotype content model. Sex Roles, 47(3-4), 99-114. https://doi.org/10.1023/A:1021020920715.

European commission. (2018). Employment and social developments in Europe 2018. Luxembourg: Publications Office of the European Union.

Finkelstein, L. M., Ryan, K. M., \& King, E. B. (2013). What do the young (old) people think of me? Content and accuracy of age-based metastereotypes. European Journal of Work and Organizational Psychology, 22(6), 633-657. https://doi.org/10.1080/1359432X. 2012.673279 . 
Fiske, S. T. (2018). Stereotype content: Warmth and competence endure. Current Directions in Psychological Science, 27(2), 67-73. https:// doi.org/10.1177/2F0963721417738825.

Fiske, S. T., Cuddy, A. J. C., \& Glick, P. (2007). Universal dimensions of social cognition: Warmth and competence. Trends in Cognitive Sciences, 11(2), 77-83. https://doi.org/10.1016/j.tics.2006.11.005.

Fiske, S. T., Cuddy, A. J. C., Glick, P., \& Xu, J. (2002). A model of (often mixed) stereotype content: Competence and warmth respectively follow from perceived status and competition. Journal of Personality and Social Psychology, 82(6), 878-902. https://doi. org/10.1037/0022-3514.82.6.878.

Fiske, S. T., Xu, J., Cuddy, A. C., \& Glick, P. (1999). (Dis)respecting versus (dis)liking: Status and interdependence predict ambivalent stereotypes of competence and warmth. Journal of Social Issues, 55(3), 473-489. https://doi.org/10.1111/0022-4537.00128.

García-Ael, C., Cuadrado, I., \& Molero, F. (2018). The effects of occupational status and sex-typed jobs on the evaluation of men and women. Frontiers in Psychology, 9, 1170. https://doi.org/10.3389/ fpsyg.2018.01170.

Goldberg, C. B., Finkelstein, L. M., Perry, E. L., \& Konrad, A. M. (2004). Job and industry fit: The effects of age and gender matches on career progress outcomes. Journal of Organizational Behavior: The International Journal of Industrial, Occupational and Organizational Psychology and Behavior, 25(7), 807-829. https:// doi.org/10.1002/job.269.

Heilman, M. E. (2012). Gender stereotypes and workplace bias. Research in Organizational Behavior, 32, 113-135. https://doi.org/10.1016/j. riob.2012.11.003.

Krings, F., Sczesny, S., \& Kluge, A. (2011). Stereotypical inferences as mediators of age discrimination: The role of competence and warmth. British Journal of Management, 22(2), 187-201. https:// doi.org/10.1111/j.1467-8551.2010.00721.x.

Lahey, J. N. (2008). Age, women, and hiring: An experimental study. Journal of Human Resources, 43(1), 30-56. https://doi.org/10.1353/ jhr.2008.0026.

Lee, T. L., \& Fiske, S. T. (2006). Not an outgroup, not yet an ingroup: Immigrants in the stereotype content model. International Journal of Intercultural Relations, 30(6), 751-768. https://doi.org/10.1016/j. ijintrel.2006.06.005.
Levin, S., Sinclair, S., Veniegas, R. C., \& Taylor, P. L. (2002). Perceived discrimination in the context of multiple group memberships. Psychological Science, 13(6), 557-560.

Liebkind, K., Larja, L., \& Brylka, A. A. (2016). Ethnic and gender discrimination in recruitment: Experimental evidence from Finland. Journal of Social and Political Psychology, 4(1), 403-426. https:// doi.org/10.5964/jspp.v4i1.433.

Nelson, N. L., \& Probst, T. M. (2004). Multiple minority individuals: Multiplying the risk of workplace harassment and discrimination. In J. L. Chin (Ed.), The psychology of prejudice and discrimination: Ethnicity and multiracial identity (Vol. 2, pp. 193-217). Westport: Praeger Publishers/Greenwood Publishing Group, Inc..

Neumark, D., Burn, I., \& Button, P. (2019). Is it harder for older workers to find jobs? New and improved evidence from a field experiment. Journal of Political Economy, 127(2), 922-970. https://doi.org/10. 1086/701029.

Pedulla, D. S. (2014). The positive consequences of negative stereotypes: Race, sexual orientation, and the job application process. Social Psychology Quarterly, 77(1), 75-94. https://doi.org/10.1177/ 0190272513506229.

Petsko, C. D., \& Bodenhausen, G. V. (2019). Racial stereotyping of gay men: Can a minority sexual orientation erase race? Journal of Experimental Social Psychology, 83, 37-54. https://doi.org/10. 1016/j.jesp.2019.03.002.

Sidanius, J., \& Pratto, F. (1999). Social dominance: An intergroup theory of social hierarchy and oppression. New York, NY: Cambridge University Press. https://doi.org/10.1017/CBO9781139175043.

Statistics Sweden (2019). Invandring till Sverige. Retrieved from: https:// www.scb.se/hittastatistik/sverige-i-siffror/manniskorna-i-sverige/ invandring-till-sverige/.

Vaughn, A. A., Teeters, S. A., Sadler, M. S., \& Cronan, S. B. (2017) Stereotypes, emotions, and behaviors toward lesbians, gay men, bisexual women, and bisexual men. Journal of Homosexuality, 64(13), 1890-1911. https://doi.org/10.1080/00918369.2016. 1273718.

Publisher's Note Springer Nature remains neutral with regard to jurisdictional claims in published maps and institutional affiliations. 